\title{
Complementarity between product and process innovation in a monopoly setting.*
}

\author{
Andrea Mantovani ${ }^{\dagger}$ \\ (Received January 2005; Revised May 2005; In final form June 2005)
}

\begin{abstract}
In this paper we study complementarity between market-enhancing product innovation and cost-reducing process innovation in a monopoly setting. First we consider the possibility for a firm to alternatively invest only along one of the two directions and compare the incentives of process vs product innovation. Then we allow the firm to invest simultaneously in both activities, showing that both investment levels as well as the profit are higher than in the case of individual investment. Thus, product and process innovations are complementary and the firm always prefers the simultaneous adoption of both activities.
\end{abstract}

Keywords: Complementarity, product innovation, process innovation.

JEL classification: L12, O31.

*This paper is part of my $\mathrm{PhD}$ Thesis at CORE, Université Catholique de Louvain. I would like to thank Karen Abramyan, Rabah Amir, Claude d'Aspremont, Luca Lambertini, Giordano Mion, JacquesFrançois Thisse, Vincent Vannetelbosch, the seminar audience at Université Catholique de Louvain, the Editor, Cristiano Antonelli, and two anonymous referees for useful comments and suggestions. The usual disclaimer applies. Financial support by the University of Bologna and the Italian Ministry of Education is gratefully acknowledged for the academic year 2004-5.

†Core, 34 Voie du Roman Pays, 1348, Louvain-la-Neuve, Belgium: mantovani@core.ucl.ac.be and Department of Economics, University of Bologna, Strada Maggiore 45, I-40125 Bologna, Italy: mantovan@spbo.unibo.it 


\section{Introduction}

It has long been recognized that modern firms carry out different types of innovative activity to challenge new conditions coming from increasingly integrated and complex markets. Technologically advanced products, such as CD players, digital cameras, personal computers, and etc., are characterized by a constant improvement in the quality associated to a drop in price; meaning, producers are constantly engaged in investing both in product innovation and in process innovation.

Recent management studies have shown that successful companies invest simultaneously in different innovative activities, aiming at ameliorating the existing product and at decreasing the cost of production (see Kim and Mauborgne, 1997 and 2004). These studies criticize the conventional idea that a trade-off exists between the creation of additional value for consumers and the reduction of the production cost. Pine et al. (1993) document that more and more firms organize their production process in order to implement both incremental product innovation and process innovation.

Initially, the relationship between product and process innovation has drawn considerable attention only in empirical works (Mansfield, 1981; Scherer, 1991; Cohen and Klepper, 1996). Nonetheless, the theoretical literature has recently devoted a closer attention to this issue, mainly due to a renewed attention to the study of interconnected subsytems linked by complementarity relationships. ${ }^{1}$ The study of innovative activity has represented one of the first field where complementarity has led to very interesting results. Hence, the analysis of product and process innovation has been recently enriched by many works that focus on the possibility that some complementarities appear when the two innovative activities are taken together.

\footnotetext{
${ }^{1}$ The theory of comparative statics, initially investigated by Samuelson, resurfaced again in economics thanks to the improvement in the theory of supermodular games, introduced by Topkis (1978) and further studied by Milgrom and Roberts (1990a, 1990b, 1995), Vives (1990) and Amir (1996), inter alia. The issue of complementarity has become a leading field of research both in games with strategic complementarities among the strategies of the players and in games with players that face multidimensional strategy space.
} 
Athey and Schmutzler (1995) analyze several features of a firm's long-run decisions about organizational structure that affect its short-run innovative activity. In particular, they consider an investment in research capabilities that improves future opportunities for new product and process innovation. Product innovation is formalized as an upward shift in the demand curve, while process innovation lowers the marginal cost of production. The authors focus on the conditions under which product innovation and process innovation, as defined in this way, are complementarity and the returns accruing from one type of innovation are the highest when the firm also adopts the other type. This clearly induces the firm to implement both types of innovations at the same time.

Lin and Saggi (2002) investigate the relationship between process and product innovation both under Bertrand competition and under Cournot competition in a duopoly model with differentiated goods. Following the conventional view on the timing of adoption, they build a three stage game where firms first choose their investment in product innovation, then the investment in process innovation, and finally they compete either in prices or in quantities. ${ }^{2}$ Differently from Athey and Schmutzler's specification, product innovation affects the degree of product differentiation by reducing product substitutability. The effect on the output by the joint implementation of two activities leads to a two-way complementarity for which an investment in one makes the other more attractive. As a consequence, firms invest more in product innovation when they can undertake also process innovation. Moreover, the equilibrium level of process innovation is an increasing function of the degree of product differentiation.

\footnotetext{
${ }^{2}$ Abernathy and Utterback (1975 and 1982) and Klepper (1996) propose a "technological life-cycle" model in which firms initially direct most of their $R \& D$ resources to product innovation and then move to process innovation. The main argument is that the returns to product innovation are at highest at the very beginning because they depend on the acquisition of new consumers, while the returns to process are very attractive in a second time becuase they are proportional to the level of output produced by the firm. Adner and Levinthal (2001) recently moved some critics to what they called a "supply-side" view of technological change in favor of a "demand side" approach where technology changes are driven by the interaction between technology development and consumers' heterogeneous demands.
} 
Weiss (2003) examines the effects of the degree of competition on firms' decisions to innovate in differentiated markets. She considers the existence of strategic complementarity between product and process innovations and studies the compositions of firms' portfolio. She found that firms favor product innovations if they produce close substitutes (so competition is severe), while they favor process innovations if products are differentiated (so competition is less severe). Bandyopadhyay and Rajat (2004) analyze complementarity between process and product innovation where process innovation reduces the marginal cost of quality. Lambertini $(2003,2004)$ and Lin (2004) study the incentives to carry out product and process innovation by a multiproduct monopoly. Product innovation concerns the introduction of new varieties and it is used as a substitute for cost-reducing process innovation.

Other papers deal with the topic of product and/or product innovation without taking into explicit account the issue of complementarity. Lambertini and Orsini (2000) analyze the incentive to introduce process and product innovation in a vertically differentiated monopoly. Rosenkranz (2003) considers a Cournot duopoly model with horizontal differentiation where firms simultaneously choose the product characteristic and the unit cost. Eswaran and Gallini (1996) examine the role of patent policy in redirecting the mix of product and process innovation towards a more efficient technological change. Bonanno and Haworth (1998) provide an interesting duopoly model which explains the R\&D choice according to the type of competitive regime where firms operate (Cournot vs. Bertrand), even if firms are not allowed to conduct both types of R\&D. Filippini and Martini (2002) extend the model of Bonanno and Haworth in that the firms simultaneously decide on the innovation to be carried out.

At this point, a cautionary note on the definition of product innovation has to be raised in order to fully comprehend the purpose of this work. While a certain homogeneity can be found in the literature regarding process innovation, and the related cost function, much more uncertainty lies around the notion of product innovation, as it emerges from the aforementioned papers. While the outcome generally associated to process innovation 
is the reduction of the marginal cost of production, at least two different specifications of product innovation appears in the literature: horizontal product innovation, aimed at decreasing the degree of substitutability among goods, and vertical product innovation, that basically favors the creation of higher quality products or the improvement of existing ones. ${ }^{3}$ Investing in horizontal product innovation implies to different objectives, methods, and strategies than from investing in vertical product innovation.

A further complication arises from how advertising has been defined in the literature. Advertising has been classified in fact either as informative or as persuasive. Informative advertising is commonly viewed to shift the demand curve upward, while persuasive advertising contributes to a kind of 'perceived' product differentiation by creating brand loyalty. ${ }^{4}$ The effects associated to advertising efforts are thus somewhat similar to those derived from product innovation.

In order to avoid confusion, one could use a general definition of market-enhancing innovative activity to describe the expansion of the demand generated by both product innovation and informative advertising. Nonetheless, throughout the paper, the term product innovation will be used to simplify the terminology, but with the caveat that what we really have in mind is an activity that yields market expansion, as in Athey and Schmutzler (1995).

The present paper provides a theoretical contribution to the study of complementarity among different innovative activities. We analyze a monopoly case where the firm faces the possibility of investing both in product and in process innovation. A monopoly setting allows for a specific analysis of the internal structure of the firm in isolation. We evaluate whether the firm finds it convenient to finance innovative activity, and along which direction. As we introduced before, product innovation shifts the demand curve by increasing consumers' willingness to pay, while process innovation takes the conventional form of a reduction in the unit cost of production.

\footnotetext{
${ }^{3}$ This initial classification has been widely adopted after the work of Lancaster (1979).

${ }^{4}$ For a discussion of the theories of advertising and the evidence of its use by firms, see Pepall, Richards and Norman (1999, Ch 10), Friedman (1983) and Martin (2002, Ch. 9).
} 
We initially consider the alternative for the firm to invest only along one direction and compare the profitability of process innovation vis à vis product innovation. ${ }^{5}$ Two factors will determine which innovative activity has to be carried out: (i) the relative efficiency of product vs process innovation; (ii) the potential market expansion vs the potential cost reduction. The first factor reflects the conventional approach based on comparing the cost of implementing different innovative activities, while the second factor points out that initial conditions may play a fundamental role in such a decision.

The second part of the paper deals with the possibility for the firm to invest in both activities at the same time. The aim is to show that demand enhancing product innovation and cost reducing process innovation are complementary. Thus, the firm obtains a higher profit when it invests simultaneously along both directions, because the gains brought about by the market enlargement expand the returns arising from the reduction of the unit cost of production. Moreover, we verify that complementarity holds even in circumstances where the firm is impeded from market constraints to invest at the optimal level. This result has important managerial implications. Whenever two or more activities display complementarity, the firm should not be tempted to decentralize its innovative operations in an attempt to find out which one is more profitable alone. On the contrary, a simultaneous investment in both options generates a profit that is higher than the sum of the profit gains derived from the two separate activities.

The paper proceeds as follows: In Section 2 we present the basic model and consider the cases where the firm invests only along one direction; either process or product innovation. Section 3 provides a comparison between the two types of innovative activities. In Section 4 we move to the case where the firm invests in both activities at the same time, focusing on the presence of complementarity and its effects on equilibrium investment levels and overall profit. Section 5 concludes the paper.

\footnotetext{
${ }^{5}$ Halmenschlager (2004) considers a modification of the standard two-stage model wherein two high-cost firms conduct cost-reducing $\mathrm{R} \& \mathrm{D}$, in a setting with spillovers, and then compete à la Cournot against a low-cost firm that does not engage in R\&D.
} 


\section{The model}

Consider a monopoly case where a firm produces a homogeneous good at the marginal cost $c$. The inverse demand function is linear and given by

$$
p=a-b q
$$

where $a$ represents the initial marginal willingness to pay and $b$ the slope (in absolute value) of the demand function. We assume that the firm produces without incurring in any fixed cost. The profit function is then given by:

$$
\pi=(p-c) q
$$

where $c$ is the unitary cost of production. We follow the usual assumption $a>c$. From

profit maximization we get the equilibrium quantity $q^{*}=\frac{a-c}{2 b}$ by which it can be easily computed the equilibrium profit:

$$
\pi^{*}=\frac{(a-c)^{2}}{4 b}
$$

Let us introduce the alternative for the monopolist to activate $\mathrm{R} \& \mathrm{D}$ along two different directions, either process innovation or product innovation.

\subsection{Process innovation}

The firm is allowed to invest in a type of $R \& D$ that lowers the marginal cost of production, i.e. it does process innovation. Following the common assumption of diminishing returns for R\&D expenditures (see d'Aspremont and Jacquemin, 1988; Qiu, 1997), the cost is given by $c(x)=\gamma \frac{x^{2}}{2}$, where $x$ indicates the investment level in process $\mathrm{R} \& \mathrm{D}$ while $\gamma$ inversely measures the efficiency of such $R \& D$ technology: the higher its value, the more expensive (i.e. the less efficient) is process $\mathrm{R} \& \mathrm{D}$, and viceversa. The profit function becomes:

$$
\pi_{x}=\frac{(a-c+x)^{2}}{4 b}-\gamma \frac{x^{2}}{2}
$$


The monopolist maximizes the profit w.r.t. $x$; the profit function is concave when $\gamma>\gamma_{1}=\frac{1}{2 b}$ and by using first-order conditions we get the equilibrium investment level in process R\&D:

$$
x^{*}=\frac{a-c}{2 b \gamma-1}
$$

Moreover, we take into account the usual feasibility condition guaranteeing the presence of non-negative costs of production. This requires $x^{*} \leq c$, where $c$ represents an upper bound in the possibility to decrease production costs by means of a cost-reducing innovative activity, and this holds when:

$$
\gamma \geq \gamma_{2}=\frac{a}{2 b c}
$$

It is easy to verify that $\gamma_{2}>\gamma_{1}$. In $\gamma_{1}<\gamma<\gamma_{2}$, the profit function is concave in $x$ but the optimal value $x^{*}$ is out of reach, given that it would entail a negative cost of production. Thus, the monopolist sets $x=c$ and it obtains the profit

$$
\pi_{c}=\frac{a^{2}-2 b c^{2} \gamma}{4 b}
$$

which is always positive and greater than (3) in the interval under consideration.

When $\gamma \geq \gamma_{2}$ the monopolist is 'free' to select the optimal investment level (5) and gets:

$$
\pi_{x}^{*}=\frac{\gamma(a-c)^{2}}{2(2 b \gamma-1)}
$$

Lastly, in $0<\gamma<\gamma_{1}$ the profit function is convex in $x$ and one has to compare the profits accruing at the extrema of the variable choice, i.e. $\pi_{c}$ (where $x=c$ ) vis à vis $\pi^{*}$ (where $x=0$ ). It is straightforward to verify that $\pi_{c}>\pi^{*}$ and the firm invests in process innovation up to the admissible limit, due to the very high efficiency of such activity (very low values of $\gamma$ ). We can summarize the above discussion as follows:

Remark 1 When $0<\gamma \leq \gamma_{2}$, process $R \& D$ is very efficient, the firm sets $x=c$ and obtains profit $\pi_{c}$. On the other hand, when $\gamma>\gamma_{2}$, process $R \& D$ is less efficient than before, the firm chooses $x=x^{*}<c$ and gets profit $\pi_{x}^{*}$. 


\subsection{Product innovation}

The firm invests in demand-enhancing product innovation to raise consumers' reservation price. Similarly to the previous case, the cost is given by $c(y)=\delta \frac{y^{2}}{2}$, where $y$ indicates the investment level and $\delta$ inversely measures the efficiency of product innovation R\&D. We assume that implementing product innovation shifts the market demand outward. The profit function becomes:

$$
\pi_{y}=\frac{(a-c+y)^{2}}{4 b}-\delta \frac{y^{2}}{2}
$$

which is concave w.r.t. $y$ when $\delta>\delta_{1}=\frac{1}{2 b}$. In this case, the first-order condition gives the equilibrium investment level in product $R \& D$ :

$$
y^{*}=\frac{a-c}{2 b \delta-1}
$$

As for feasibility requirements, we assume that the demand expansion due to the increase in the reservation price cannot exceed a maximum level parameterized by $A$. This accounts for the fact that there cannot be unlimited expansion of the market. ${ }^{6}$ Moreover, it will allow for a comparison between cost-reducing process innovation and market-expanding product innovation based also on the initial conditions of the market, as we will consider in the next section.

As a consequence, we impose an upper bound on the optimal investment level in product innovation given by $y^{*} \leq A-a$, which holds if:

$$
\delta \geq \delta_{2}=\frac{A-c}{2 b(A-a)} .
$$

Notice that $\delta_{2}>\delta_{1}$; as before, we have to consider two subintervals. In $\delta_{1}<\delta<\delta_{2}$ the equilibrium level $y^{*}$ exceeds the maximum demand enlargement; the monopolist is obliged to fix $y=A-a$, obtaining

$$
\pi_{A}=\frac{(A-c)^{2}-2 b(A-a)^{2} \delta}{4 b}
$$

\footnotetext{
${ }^{6}$ If we do not restrict the potential market expansion, the optimal investment in product R\&D is still given by (10) for $\delta>\delta_{1}$, while it would go to infinity for $\delta \leq \delta_{1}$, being the profit function convex with respect to $R \& D$ investment.
} 
which is always positive and greater than (3) in the region that we consider.

In $\delta \geq \delta_{2}$ the monopolist chooses the optimal investment level (10) and gets:

$$
\pi_{y}^{*}=\frac{\delta(a-c)^{2}}{2(2 b \delta-1)}
$$

Finally, in $0<\delta<\delta_{1}$, the profit function is convex in $y$ and by comparing $\pi_{A}$ (where $y=A-a$ ) vis à vis $\pi^{*}$ (where $y=0$ ) we verify that $\pi_{A}>\pi^{*}$ : the firm invests in product up to the admissible market expansion. Then:

Remark 2 When $0<\delta \leq \delta_{2}$, product $R \& D$ is very efficient, the firm sets $y=A-a$ and obtains $\pi_{A}$. On the other hand, when $\delta>\delta_{2}$ product $R \& D$ is less efficient than before, the firm chooses $y=y^{*}<A-a$ and gets profit $\pi_{y}^{*}$.

Caveat: market expansion and utility function In our model, product innovation shifts the demand function by raising consumers' willingness to pay. As we have already pointed out in the introductory section, the net effect of such $R \& D$ investment is equivalent to an investment in advertising that shifts the demand curve. In general, any demandenhancing investment activity gives rise to a complex issue if it also shifts the individual utility function from which the demand curve is derived, as initially pointed out by Dixit and Norman (1978). ${ }^{7}$ The usual criticism regarding the welfare comparisons also applies to the profit comparisons carried out in our model.

We can therefore use a relative measure that captures the ability of the monopolist to extract profit from total surplus, usually defined as the sum of consumers' and producers' surplus. In the benchmark case, where the monopolist does not carry out any investment activity, the demand remains at the initial level (1) and profit is given by (3). Total surplus can be easily computed and amounts to:

$$
T S^{*}=\frac{3(a-c)^{2}}{8 b} .
$$

\footnotetext{
${ }^{7}$ See also Martin (2002), Ch. 9, for a comprehensive discussion.
} 
It follows immediately that:

$$
E E^{*}=\frac{\pi^{*}}{T S^{*}}=\frac{2}{3}
$$

where $E E$ stands for extraction efficiency, the fraction of total surplus that the monopolist is able to capture.

Take now into account the case where the monopolist is allowed to invest in product innovation and consider the interior and admissible solution (10), which holds for $\delta>\delta_{2}$. Total surplus and firm's extraction efficiency are respectively given by:

$$
\begin{gathered}
T S_{y}=\frac{\delta(a-c)^{2}(3 b \delta-2)}{2(1-2 b \delta)^{2}} . \\
E E_{y}=\frac{\pi_{y}}{T S_{y}}=\frac{1-2 b \delta}{1-3 b \delta} .
\end{gathered}
$$

As it can be easily noticed:

$$
E E^{*}>E E_{y}
$$

meaning that the fraction of total surplus that the monopolist is able to extract diminishes in the product innovation case. The same result can be shown to hold also for $\delta<\delta_{2}$.

In absolute terms, however, cash flows are higher in case of demand expansion generated by product $\mathrm{R} \& \mathrm{D}$ than in case of no investment. As a consequence, the monopolist decides to invest in product innovation. A similar reasoning applies for the process innovation case.

\section{Process vs product innovation}

In the previous part of the paper we have considered the choice of process R\&D separately from the choice of product R\&D. Recall that the monopolist sets $x=x^{*}<c$ for $\gamma>\gamma_{2}$ and $x=c$ for $0<\gamma \leq \gamma_{2}$, while it chooses $y=y^{*}<A-a$ for $\delta>\delta_{2}$ and $y=A-a$ for $0<\delta \leq \delta_{2}$

In Figure 1 we represent all the possible regions of interest in the comparison between the two types of innovations. 


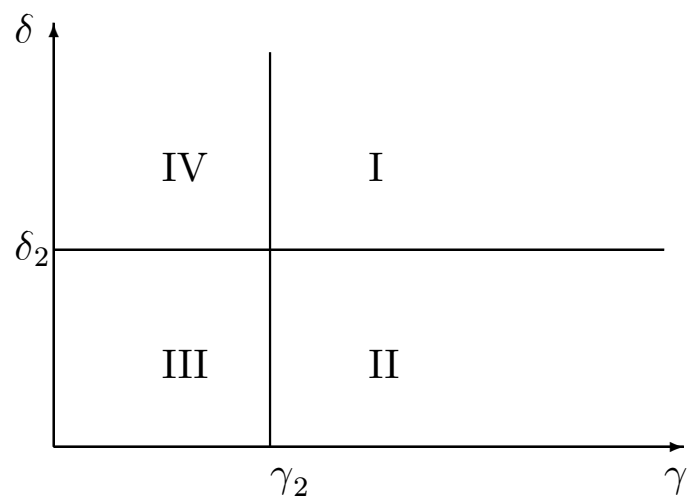

Figure 1: Process vs product R\&D

We have then to perform the following comparisons:

- in region I $\left(\gamma>\gamma_{2}\right.$ and $\left.\delta>\delta_{2}\right): \pi_{x}^{*}$ vs $\pi_{y}^{*}$;

- in region II $\left(\gamma>\gamma_{2}\right.$ and $\left.\delta<\delta_{2}\right): \pi_{x}^{*}$ vs $\pi_{A}$;

- in region III $\left(\gamma<\gamma_{2}\right.$ and $\left.\delta<\delta_{2}\right): \pi_{c}$ vs $\pi_{A}$;

- in region IV $\left(\gamma<\gamma_{2}\right.$ and $\left.\delta>\delta_{2}\right): \pi_{y}^{*}$ with $\pi_{c}$.

First of all we compare $\gamma_{2}$ and $\delta_{2}$ and find that:

$$
\gamma_{2}>(<) \delta_{2} \text { iff } A-a>(<) c
$$

Definition 1 The potential increase in consumers' reservation price is large when $A-a>$ $c$, while it is small otherwise.

When the potential increase in consumers' reservation price is large (small), product (process) innovation is obviously likely to be more profitable for the firm. The following analysis will shed light on the effect of product and process innovation when deciding between the two activities.

Let us begin from Region I. It is easy to prove that:

$$
\pi_{x}^{*}<(>) \pi_{y}^{*} \text { when } \delta<(>) \gamma
$$


Furthermore, when $\delta<(>) \gamma$ then $y^{*}>(<) x^{*}$. In line with the theoretical assumption of our model, when $\delta<\gamma$, the firm prefers to invest in product innovation because it can be implemented at a lower cost. The opposite holds when $\delta>\gamma$ and the firm chooses process innovation instead.

In the other regions the result crucially depends not only on the relative efficiency of process vs product innovation, but also on the potential shift in the demand function as compared to the potential reduction in the marginal cost of production. We find the following results:

- When $A-a>c$ :

- in Region II $\pi_{A}>\pi_{x}^{*}$;

- in Region III $\pi_{A}>\pi_{c}$ for $0<\delta<\frac{(A-c)^{2}+2 b c^{2} \gamma-a^{2}}{2(A-a)^{2} b}=\delta_{A}\left(<\delta_{2}\right)$;

- in Region IV $\pi_{y}^{*}>\pi_{c}$ for $0<\delta<\frac{2 b c^{2} \gamma-a^{2}}{2 b c^{2}(1+2 b \gamma)-4 a b c}=\delta_{c}\left(>\delta_{2}\right)$.

- When $A-a<c$ :

- in Region II $\pi_{x}^{*}>\pi_{A}$ for $0<\gamma<\frac{(A-c)^{2}-2(A-a)^{2} b \delta}{2 b(A-a)[A+a-2 c-2(A-a) b \delta]}=\gamma_{A}$ $\left(>\gamma_{2}\right)$

- in Region III $\pi_{c}>\pi_{A}$ for $0<\gamma<\frac{a^{2}-(A-c)^{2}+2(A-a)^{2} b \delta}{2 b c^{2}}=\gamma_{c}\left(<\gamma_{2}\right)$;

- in Region IV $\pi_{c}>\pi_{y}^{*}$.

Moreover, it is important to notice that the size of the four regions, being defined by the values taken by $\gamma_{2}$ and $\delta_{2}$, depends in turn on the relative shift in the demand function, as we know from (19). In Figure 2 we represent the decision choice between process and product innovation in the $\{\gamma, \delta\}$ space. Following the previous definition, in the left panel (Figure 2a) the potential demand expansion is large, while in the right panel (Figure 2b) it is small. ${ }^{8}$

\footnotetext{
${ }^{8}$ We draw both pictures by taking $b=1, c=1, a=1.5$. In the left panel we further impose that $A=3$, hence $A-a>c$, while in the right panel $A=2$ and $A-a<c$.
} 


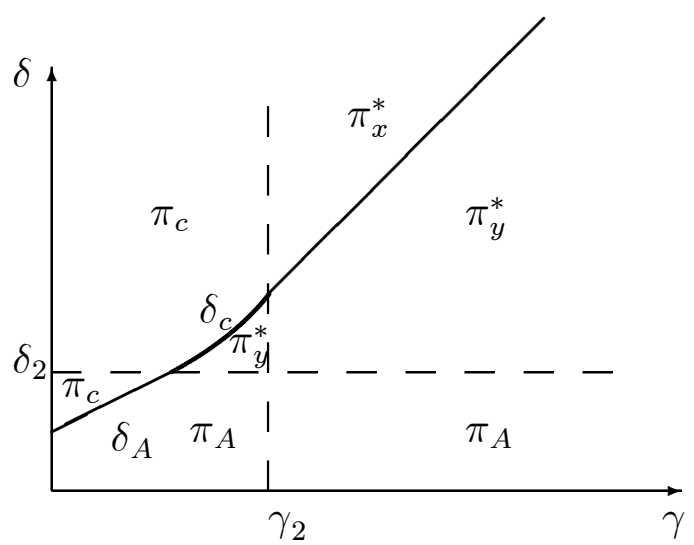

Figure 2a: $A-a>c$

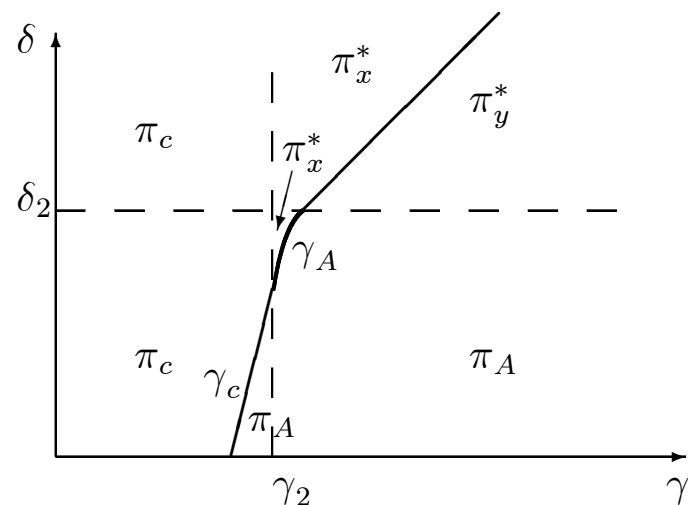

Figure 2b: $A-a<c$

The above representation clarifies the importance of initial conditions in deciding whether to invest in product or in process innovation. If the potential demand enhancement is large, then the firm prefers product innovation. In particular, when both activities are very efficient, i.e. when both $\gamma$ and $\delta$ are sufficiently low, the firm chooses product innovation because it arrives at the maximum expansion of the demand by spending a limited amount of money. Not only that product innovation is very efficient, but also that the perspective of market enlargement is very appealing. The opposite holds when the potential demand expansion is small: the firm prefers process innovation because it finds unprofitable to devote resources to product $R \& D$ in a situation where the perspectives of raising consumer's reservation price are limited.

The following proposition summarizes the above discussion:

Proposition 2 When the potential demand expansion is large, i.e. when $A-a>c$, the firm prefers to invest in product innovation, while the opposite holds when $A-a<c$.

Hence, the choice between product and process innovation is dictated not only by the relative efficiency of the two activities but also by the potential demand expansion as compared to potential cost reduction. This result clearly indicates that initial conditions play a crucial role in determining the investment decisions between product and process innovation. In other words, it suggests a closer attention to the nature of the product 
itself. In case of technologically "mature" goods, the possibility of further shifting market demand is somehow limited and the firm concentrates on process innovation. On the contrary, new-to-the-market goods are usually very attractive for consumers and product innovation turns out to be more profitable.

\section{Process and product innovation}

In this section we analyze the possibility for the firm to invest in both kinds of R\&D. The aim is to show that process and product $\mathrm{R} \& \mathrm{D}$, as they are defined in our model, are complementary.

The profit function is given by:

$$
\pi_{x, y}=\frac{(a-c+x+y)^{2}}{4 b}-\gamma \frac{x^{2}}{2}-\delta \frac{y^{2}}{2}
$$

Separate concavity with respect to each investment level still requires:

$$
\frac{\partial \pi_{x, y}^{2}}{\partial x^{2}}<0 \text { for } \gamma>\gamma_{1} \text { and } \frac{\partial \pi_{x, y}^{2}}{\partial y^{2}}<0 \text { for } \delta>\delta_{1},
$$

while joint concavity with respect to both investment decisions holds if:

$$
\gamma>\gamma_{3}=\frac{\delta}{2 b \delta-1}
$$

where $\gamma_{3}>\gamma_{1}$. It is immediate to prove that:

Proposition 3 Process and product innovation are complementary activities for the firm.

Proof The two activities are complementary because:

$$
\frac{\partial^{2} \pi_{x, y}}{\partial x \partial y}=\frac{\partial^{2} \pi_{x, y}}{\partial y \partial x}=\frac{1}{2 b}>0
$$

Following Topkis (1978), in fact, a function is supermodular when cross-partial derivatives between each pair of variables are positive. This formalizes the notion of complementary investment opportunities. Any increase in one of the two variables raises the 
profitability of implementing the other. The economic interpretation is that the marginal returns from a demand enhancement investment activity increase with a reduction of the marginal cost due to process innovation. Alternatively, since supermodularity is a twoway complementarity relationship, an equivalent interpretation is that the benefit that the firm derives from a reduction of the marginal cost of production increases with the overall demand, i.e. with the acquisition of new consumers. ${ }^{9}$

Assume for the moment that (22) holds; equilibrium investment levels are:

$$
\begin{gathered}
x_{x, y}^{*}=\frac{\delta(a-c)}{2 b \gamma \delta-\gamma-\delta}>0, \\
y_{x, y}^{*}=\frac{\gamma(a-c)}{2 b \gamma \delta-\gamma-\delta}>0 .
\end{gathered}
$$

Obviously, the firm devotes more resources to product (process) innovation when $\gamma>\delta$ $(\gamma<\delta)$ and its R\&D portfolio depends on the relative efficiency of the two activities. It is easy to show that:

$$
x_{x, y}^{*}>x^{*} \text { and } y_{x, y}^{*}>y^{*} .
$$

Due to the complementarity effect, the investment level in both process innovation and product innovation is higher than in the case of investment along one single direction.

As for the equilibrium profit, by plugging (24) and (25) in (20) and rearranging, we get:

$$
\pi_{x, y}^{*}=\frac{(a-c)^{2} \gamma \delta}{2(2 b \gamma \delta-\gamma-\delta)}>0
$$

\footnotetext{
${ }^{9}$ It is easy to demonstrate that the same result holds for a multiproduct monopoly. Consider a symmetric differentiated demand system $p_{i}=a-q_{i}-d q_{j}, i=1,2$, where $d \in[0,1]$ denotes product substitutability. Assume the monopolist invests in process innovation to reduce the cost of producing the first product and in product innovation to increase market size $a$. Given that $a$ is common for both firms, crosspartial derivatives are positive and the two actiities are indeed complementary. We prefer to use a more simple presentation as it is laid out in the paper as no significant qualitative changes are obtained in the multiproduct setting,
} 
which is higher than (8) and (13).

One may argue that the results derived above are strongly affected by the adoption of a linear demand function, given that the solution basically depends on a change in $(a-c)$. Even if similar results can be obtained by considering more complex demand and/or cost functions, we prefer to present an easy case where complementarity always holds. In fact, this allows to propose a model that combines technological and demand factors and to stress on the role played by initial conditions. Moreover, due to its simple structure, we are able to completely characterize the equilibrium solutions also in presence of market constraints, as it will be discussed in the following subsection.

\subsection{Market constraints}

In this section we consider the feasibility constraints that the firm faces when invests simultaneously in product and process innovation. Under (22) equilibrium investment levels are (24) and (25). Nonetheless, we need to verify the feasibility conditions, $x_{x, y}^{*} \leq c$ and $y_{x, y}^{*} \leq A-a$, yielding:

Lemma 1 (i) $x_{x, y}^{*} \leq c$ when $\gamma \geq \gamma_{4}=\frac{a \delta}{c(2 b \delta-1)}$, with $\gamma_{4}>\gamma_{3}$, (ii) $y_{x, y}^{*} \leq A-a$ when $\gamma$ $\geq \gamma_{5}=\frac{(A-a) \delta}{2 b \delta(A-a)-(A-c)}$, with $\gamma_{5}>\gamma_{4}$ in $\delta_{2} \leq \delta \leq \delta_{3}=\frac{A}{2 b(A-a)}$.

In Figure 3 we represent in the $\{\delta, \gamma\}$ plan the additional feasibility requirements: 


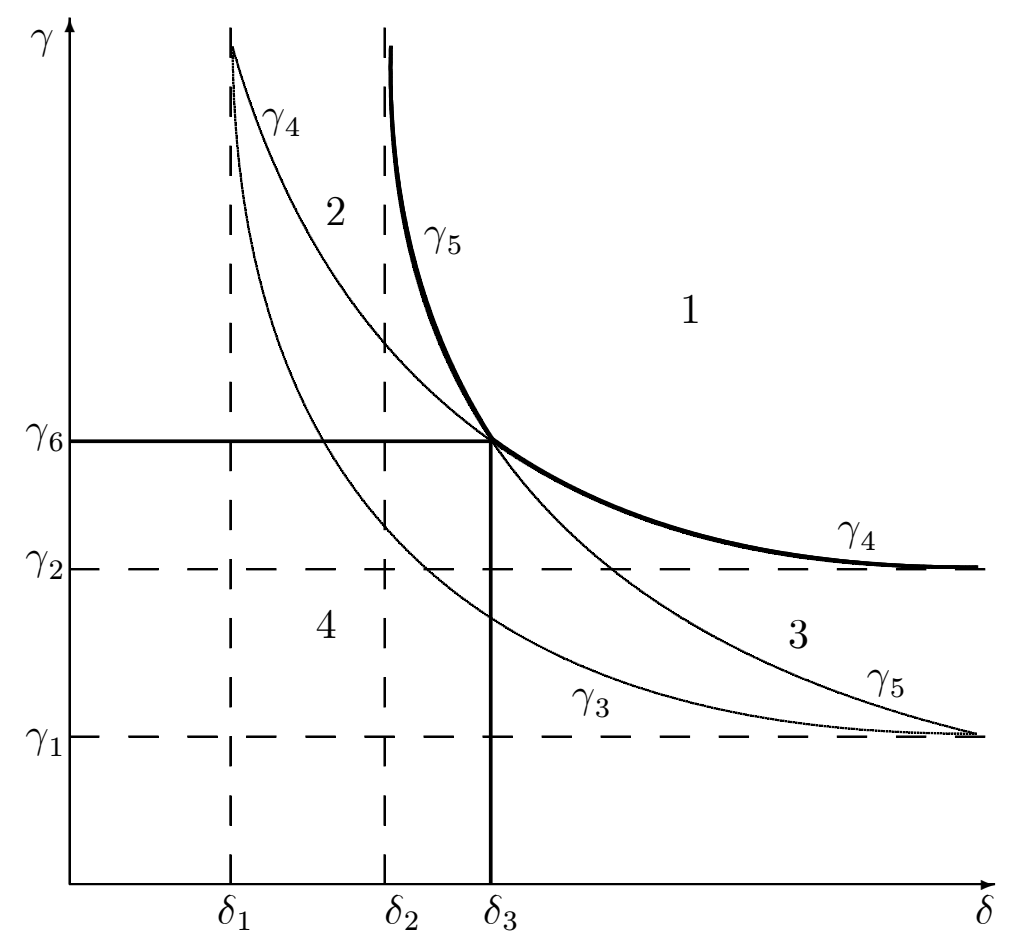

Figure 3: Feasibility conditions

In Region 1, where $\gamma>\max \left\{\gamma_{4}, \gamma_{5}\right\}$, the firm is 'free' to choose (24) and (25). As we argued before, the equilibrium investment level in both activities as well as the profit are higher than in the case of investment only along one direction.

In Region 2, where $\delta<\delta_{3}$ and $\gamma_{4}<\gamma<\gamma_{5}$, the firm is constrained on product innovation. As a consequence, it sets the highest admissible level, $y=A-a$, and recomputes the optimal investment in process innovation, which is equal to:

$$
\widehat{x}_{a}=\frac{A-c}{2 b \gamma-1}
$$

Concavity of the profit function now only requires $\gamma>\gamma_{1}$. It is straightforward to prove that $x^{*}<\widehat{x}_{a}<x_{x, y}^{*}$. On the one hand, $\widehat{x}_{a}>x^{*}$ means that the equilibrium level of process innovation in this joint adoption 'constrained' case is still higher than in the case of process innovation alone. On the other hand, $\widehat{x}_{a}<x_{x, y}^{*}$ indicates that such a level it is smaller than in the unconstrained case; due to a weaker complementarity effect that derives from an investment in product innovation lower than in the optimal value. Moreover, notice 
that $\widehat{x}_{a}<c$ for $\gamma>\gamma 6=\frac{A}{2 b c}(>\gamma 1)$ and Region 2 expands then to include $\delta<\delta_{3} \cup$ $\gamma_{6}<\gamma<\gamma_{5}$. The equilibrium profit becomes:

$$
\widehat{\pi}_{a}=\frac{(A-c)^{2} \gamma-(A-a)^{2} \delta(2 b \gamma-1)}{2(2 b \gamma-1)}>0
$$

and it can be easily proved that it is lower than the profit obtained in Region 1 . One might wonder whether the monopolist still prefers to invest in both activities when at least one of them is constrained by the market conditions. By considering all the admissible alternatives, i.e. $\pi_{x}^{*}, \pi_{y}^{*}$ (for $\delta>\delta_{2}$ ) and $\pi_{a}$ (for $0 \leq \delta \leq \delta_{2}$ ) it is possible to show that $\widehat{\pi}_{a}$ corresponds to the highest obtainable profit. Hence, in this parameter's region, there still exists a sufficient complementarity to make the monopolist willing to invest in both directions.

In Region 3, where $\delta>\delta_{3}$ and $\gamma_{5}<\gamma<\gamma_{4}$, we face the opposite situation with respect to the previous case, but the results are indeed analogous. The monopolist is obliged to fix $x=c$, hence it recomputes the optimal level of product innovation, given by:

$$
\widehat{y}_{c}=\frac{a}{2 b \delta-1}
$$

and $y^{*}<\widehat{y}_{c}<y_{x, y}^{*}$. Concavity holds if $\delta>\delta_{1}$, while $\widehat{y}_{c}<A-a$ for $\delta>\delta_{3}$. The area that we consider expands to $\delta>\delta_{3} \cup \gamma<\gamma_{4}$. The equilibrium profit is then:

$$
\widehat{\pi}_{c}=\frac{a^{2} \delta-c^{2} \gamma(2 b \delta-1)}{2(2 b \delta-1)}>0 .
$$

The monopolist is obliged to set a level of process innovation lower than the optimal one and this reduces both the equilibrium level of product innovation and the equilibrium profit. By considering all the admissible alternatives, i.e. $\pi_{x}^{*}, \pi_{y}^{*}$ and $\pi_{c}$ it is possible to show that $\widehat{\pi}_{c}$ corresponds to the highest admissible profit. Complementarity is again strong enough for the monopolist to invest in both activities.

Finally, in Region 4, that after the previous considerations amounts to $\delta<\delta_{3} \cup$ $\gamma<\gamma_{6}$, the firm either faces constraints on both directions or neither joint concavity nor single concavity are preserved. For example, in $\gamma>\gamma_{3}$, the two activities are still 
complementary and the profit function is joint concave but the optimal investment levels cannot be reached. The firm could set $x=c$ and $y=A-a$, thus yielding

$$
\widehat{\pi}_{a c}=\frac{A^{2}-2 b c^{2} \gamma-2 b(A-a)^{2} \delta}{4 b}
$$

that is always positive in the region of parameters that we consider. Moreover, it is easy to demonstrate that such a profit is the highest the firm can obtain. The same argument holds also when $\gamma<\gamma_{3}$ and either the profit function is not jointly concave or it is concave only w.r.t. one investment activity, and it even holds when it is convex w.r.t both process and product innovation investment levels.

We can summarize the main results as follows:

- 1) $x=x_{x, y}^{*}, y=y_{x, y}^{*}$ and $\pi=\pi_{x, y}^{*}$;

- 2) $x=\widehat{x}_{a}, y=A-a$ and $\pi=\widehat{\pi}_{a}$;

- 3) $x=c, y=\widehat{y}_{c}$ and $\pi=\widehat{\pi}_{c}$;

- 4) $x=c, y=A-a$ and $\pi=\widehat{\pi}_{a c}$.

From the above discussion, it emerges that:

Proposition 4 Complementarity between process innovation and product innovation is preserved under the feasibility constraints on the equilibrium investment levels.

As a result, the firm always prefers to activate both types of R\&D activity, even in cases where the feasibility constraints limit the resources that can be invested. However, this happens when either one or both innovative activities are very efficient and the firm decides to invest a lower-than-optimal level and enjoy complementarity gains.

Finally, it is worth noting that the combination between technological features, which is summarized by the relative efficiency of process and product innovation, and initial conditions on market demand and cost structure determine the amount of resources devoted to each innovative activity. 


\subsection{Cost complementarity}

As it stands, the overall effect of process innovation is exactly the same as that of product innovation, given that both shift the demand curve outward. It can be argued that the separation of the two innovative activities taken into account in our model is somewhat unnecessary. However, this simply implies that a joint implementation of both innovative activities yields a higher return for the firm even without an explicit cost complementarity between the two options. When there are diminishing returns for $R \& D$ expenditures, two separated units working on demand expansion, one directly through an increase of consumers' willingness to pay and the other indirectly through a cost reduction, exploit complementarity and yield a higher profit for the firm. Indeed, if implementing them jointly were less costly than implementing them separately, then there would be a new incentive on the cost side for joint implementation, which we have not considered. This incentive would reinforce the demand side complementarity analyzed in this paper.

The presence of cost complementarity can be examined by considering a multiproduct monopolist that sells two different goods in two distinct markets. Demand functions are given by

$$
p_{i}=a_{i}-b_{i} q_{i}, i=1,2 \text {. }
$$

We assume that the monopolist does not practice any form of price discrimination among consumers. The monopoly profit without R\&D investment is given by:

$$
\Phi=\sum_{i}\left(p_{i}-c_{i}\right) q_{i}
$$

By first-order conditions it is easy to compute optimal quantities and optimal profit, respectively given by: ${ }^{10}$

$$
q_{i}^{*}=\frac{a_{i}-c_{i}}{2 b_{i}}
$$

\footnotetext{
${ }^{10}$ Second order conditions are always satisfied, as it can be easily checked.
} 


$$
\Phi^{*}=\frac{b_{2}\left(a_{1}-c_{1}\right)^{2}+b_{1}\left(a_{2}-c_{2}\right)^{2}}{4 b_{1} b_{2}}
$$

Suppose now that the monopolist invests to reduce the production cost of the first product and to expand the demand of the second product. The overall investment cost function is given by $C(x, y)=\gamma\left(x^{2} / 2\right)+\delta\left(y^{2} / 2\right)$, where $x$ and $y$ respectively denote process and product innovation, exactly as before. The profit function is therefore defined as:

$$
\Phi_{x, y}=\frac{b_{2}\left(a_{1}-c_{1}+x\right)^{2}+b_{1}\left(a_{2}+y-c_{2}\right)^{2}}{4 b_{1} b_{2}}-\gamma \frac{x^{2}}{2}-\delta \frac{y^{2}}{2}
$$

It can be easily checked that the cross-partial derivatives $\frac{\partial^{2} \pi_{x, y}}{\partial x \partial y}$ and $\frac{\partial^{2} \pi_{x, y}}{\partial y \partial x}$ are equal to zero and no complementarity relation holds. However, assume the presence of a term that measures the interaction between the two R\&D activities in the cost function, which becomes $C^{\prime}(x, y)=\gamma\left(x^{2} / 2\right)+\delta\left(y^{2} / 2\right)-\beta x y$, where $\beta>0$ indicates an additional marginal benefit from investing in one $R \& D$ activity when the firm is already investing in the other R\&D activity. The profit function becomes then:

$$
\Phi_{x, y}^{\prime}=\frac{\left(a_{1}-c_{1}+x\right)^{2}+\left(a_{2}+y-c_{2}\right)^{2}}{4}-\gamma \frac{x^{2}}{2}-\delta \frac{y^{2}}{2}+\beta x y
$$

It is effortless to prove that the cross-partial derivatives are positive (both equal to $\beta$ ) and the two activities are characterized by cost complementary.

\section{Conclusions}

We have investigated a monopoly case where a firm can invest in product innovation that expands market demand and in process innovation that reduces the marginal cost of production. We have initially considered the two activities as separate decisions and have drawn interesting conclusions on whether the firm prefers to invest in process innovation or in product innovation. In particular, we have focused on the role played by market's initial conditions, that affect the potential demand improvement vs the effective cost abatement.

The second part of the paper has dealt with the simultaneous implementation of process and product innovation. We have shown the existence of complementarity between a 
demand-enhancing R\&D activity and a cost-reducing one. It follows that the firm always prefers to invest in both activities at the same time to maximize its profit. Furthermore, we have demonstrated that such complementarity is preserved even in the case of constraints on equilibrium investment levels. In other words, even in circumstances where market conditions do not allow for a considerable cost reduction and/or demand expansion, the firm gets a higher profit when investing in both activities rather than when implementing only one of them. Initial conditions act in combination with efficiency considerations to determine firm's optimal R\&D portfolio.

Finally, we have highlighted the fact that the joint implementation of both innovative activities is profit-maximizing even without an explicit cost complementarity. This reinforces the result that a joint adoption of the two innovative activities is more profitable than the adoption of a single activity.

\section{References}

[1] Abernathy, W. J. and J.M. Utterback (1975), A dynamic model of process and product innovation, Omega, 3(6), 639-656.

[2] Abernathy, W. J. and J.M. Utterback (1982), Patterns of Industrial Innovation, in: M. L. Tushman and W. L. Moore, eds., Readings in the Management of Innovation, Boston: Pitman, 97-108.

[3] Adner R. and D. Levinthal (2001), Demand Heterogeneity and Technology Evolution: Implications for Product and Process Innovation, Management Science, 47(5), 611628.

[4] Amir, R. (1996), Cournot Oligopoly and the Theory of Supermodular Games, Games and Economic Behavior, 15, 132-148.

[5] Athey, S. and A. Schmutzler (1995), Product and Process Flexibility in an Innovative Environment, RAND Journal of Economics, 26, 557-574. 
[6] Bandyopadhyay, S and A. Rajat (2004), Process and Product Innovation: Complementarity in a Vertically Differentiated Monopoly with Discrete Consumer Types, Japanese Economic Review, 55, 175-200.

[7] Bonanno, G. and B. Haworth (1998), Intensity of Competition and the Choice between Product and Process innovation, International Journal of Industrial Organization, 16, 495-510.

[8] Cohen, W. and S. Klepper (1996), Firm size and the nature of innovation within industries: The case of process and product R\&D, Review of Economics and Statistics, 78, 232-243.

[9] d'Aspremont, C. and A. Jacquemin (1988), Cooperative and Noncooperative R\&D in Duopoly with Spillovers, American Economic Review, 78 (5), 1133-1137.

[10] Dixit, A. and V. Norman (1978), Advertising and Welfare, The Bell Journal of Economics, 9, 1-17.

[11] Eswaran M. and N. Gallini (1996), Patent policy and the direction of technological change (1996), RAND Journal of Economics, 4, 722-746.

[12] Filippini, L. and G. Martini (2002), Vertical differentiation and innovation adoption. Mimeo.

[13] Friedman, J.W. (1983), Advertising and Oligopolistic Equilibrium, The Bell Journal of Economics, 14, 464-473.

[14] Halmenschlager, C. (2004), R\&D-cooperating laggards versus a technological leader, Economics of Innovation and New Technology, 13 (8), 717 - 732.

[15] Kim, W. C. and R. Mauborgne (1997), Value Innovation: The Strategic Logic of High Growth, Harvard Business Review, January-February, 103-112. 
[16] Kim, W. C. and R. Mauborgne (2004), Blue Ocean Strategy, Harvard Business Review, October, 76-84.

[17] Klepper, S. (1996), Entry, Exit and Innovation over the Product Life Cycle, American Economic Review, 86, 562-583.

[18] Lambertini, L. (2003), The Monopolist's Optimal R\&D Portfolio, Oxford Economic Papers, 55, 561-578.

[19] Lambertini, L. (2004), Process and Product R\&D by a Multiproduct Monopolist: A Reply to Lin, Oxford Economic Papers, 56, 745-749.

[20] Lambertini, L. and R. Orsini (2000), Process and product innovation in a vertically differentiated monopoly, Economic Letters, 68, 333-37.

[21] Lancaster, K. J. (1979), Variety, Equity and Efficiency, New York: Columbia University Press.

[22] Lin, P. (2004), Process and Product R\&D by a Multiproduct Monopolist, Oxford Economic Papers, 56, 735-743.

[23] Lin P. and K. Saggi (2002), Product differentiation, process R\&D, and the nature of market competition, European Economic Review, 46, 201-211.

[24] Mansfield, E. (1981), Composition of R\&D expenditures: Relationship to size of firm, concentration, and innovative output, Review of Economics and Statistics, 63, 610615.

[25] Martin, S. (2002), Advanced Industrial Economics, second edition, Oxford, Blackwell.

[26] Milgrom, P. and J. Roberts (1990a), The Economics of Modern Manufacturing: Technology, Strategy and Organization, American Economic Review, 80, 511-528.

[27] Milgrom, P. and J. Roberts (1990b), Rationalizability, Learning, and Equilibrium in Games with Strategic Complementarities, Econometrica, 58, 1255-1278. 
[28] Milgrom, P. and J. Roberts (1995), Complementarities and Fit: Strategy, Structure, and Organizational Change in Manufacturing, Journal of Accounting and Economics, 19, 179-208.

[29] Pepall, L., Richards, D. and G. Norman (1999), Industrial Organization: Contemporary Theory and Practise, New York, South-Western College Publishing.

[30] Pine, B.J., Victor, B. and A. C. Boyton (1993), Making mass customization work, Harvard Business Review, September-October, 108-119.

[31] Qiu, L. (1997), On the Dynamic Efficiency of Bertrand and Cournot Equilibria, Journal of Economic Theory, 75, 213-29.

[32] Rosenkranz, S. (2003), Simultaneous choice of process and product innovation when consumers have a preference for product variety, Journal of Economic Behavior \& Organization, 50 (2), 183-201.

[33] Samuelson, P. (1974), Complementarity, Journal of Economic Literature, 12, 12551289.

[34] Scherer, F.M. (1991), Changing Perspectives on the Firm Size Problem, in Zoltan J. and D. B. Audrestsch (eds.), Innovation and technological Change: An International Comparison, New York: Harvester Wheatsheaf, 1991.

[35] Topkis, D. (1978), Minimizing a Submodular Function on a Lattice, Operations Research, 26, 305-321.

[36] Vives, X. (1990), Nash Equilibrium with Strategic Complementarities, Journal of Mathematical Economics, 19, 305-321.

[37] Weiss, P. (2003), Adoption of Product and Process Innovations in Differentiated Markets: The Impact of Competition, Review of Industrial Organization, 23, 301-314. 